$1988,37,3$

удК 681.511 .42

Olle KOTTA

\title{
DISCRETE-TIME LINEAR-ANALYTIC SYSTEM LINEARIZATION AND DECOUPLING VIA APPLICATION OF RIGHT INVERSE SYSTEM
}

\author{
(Presented by 0. Jaaksoo)
}

\section{Introduction}

The concept of the right inverse system has been around for some considerable time with applications in constructing an input which yield some desired output. We shall show that the right inverse system has one more application in the problem of finding a dynamic open loop control under which the input-output behaviour of a given discrete time linear-analytic system becomes linear or decoupled.

In literature we can find some results considering construction linearizing and decoupling feedback controls for discrete-time linear-analytic systems $\left[{ }^{1-3}\right]$. It will be shown here how these feedback laws can be interpreted in terms of right inverse system.

\section{Problem statement} tions

Consider the linear-analytic discrete-time system described by equa-

$$
\begin{aligned}
& x(t+1)=x(t)+f_{0}(x(t))+F(x(t)) u(t), \\
& y(t)=h(x(t)), \\
& x(0)=x_{0},
\end{aligned}
$$

where the state $x(t) \in R^{n}, u(t)$ is the $m$-dimensional input/ vector, $y(t)$ is the $p$-dimensional output vector $(\mathrm{p} \leqslant m), \quad F(x(t))=\left[f_{1}(x(t)) \ldots\right.$ $\left.\ldots f_{m}(x(t))\right], f_{0}, f_{1}, \ldots, f_{m}: R^{n} \rightarrow R^{n}$ and $h: R^{n} \rightarrow R^{p}$ are analytic functions on $R^{n}$.

For system (1), (2) (provided it satisfies two conditions which will be specified in section 4) feedback control laws in the form

$$
u(t)=\alpha(x(t))+\beta(x(t)) v(t)
$$

have been found under which the input-output behaviour of the closedloop system $(1)-(3)$ becomes linear $\left[{ }^{1}\right]$ or decoupled $\left[{ }^{2,3}\right]$. In (3) $v(t) \in R^{p}$ is a new input vector and the entries of $\alpha$ and $\beta$ are real analytic functions defined on a suitable open and dense subset of $R^{n}$.

The model specifying the behaviour of the linear system is given by 
the equations [1]

$$
\begin{aligned}
& z_{s}^{k}(t+1)=z_{s}^{h+1}(t), \quad s=1, \ldots, p, \quad k=0, \ldots, d_{s}-1, \\
& z_{s}^{d_{s}}(t+1)=\sum_{k=1}^{p} \sum_{j=0}^{d_{k}} c_{s j}^{k} z_{k}^{j}(t)+\sum_{i=1}^{p} b_{s i} v_{i}(t), \\
& y_{s}^{*}(t)=z_{s}^{0}(t),
\end{aligned}
$$

where $c_{s j}^{k}$ and $b_{s i}$ are constants.

The model specifying the behaviour of the decoupled system is given by the equations $[2,3]$

$$
\begin{aligned}
& z_{s}^{k}(t+1)=z_{s}^{k+1}(t), \quad s=1, \ldots, p, \quad k=0, \ldots, d_{s}-1, \\
& z_{s}^{d_{s}}(t+1)=\sum_{j=0}^{d_{s}} c_{j}^{s} z_{s}^{j}(t)+\left(m^{s}+\sum_{j=0}^{d_{s}} m_{j}^{s} z_{s}^{j}(t)\right) v_{s}(t), \\
& y_{s}^{*}(t)=z_{s}^{0}(t) .
\end{aligned}
$$

The purpose of this paper is to find, via application of right inverse system, control laws under which the input-output behaviour of the nonlinear system (1), (2) satisfying the aforementioned conditions becomes linear (specified by model (4)) or decoupled (specified by model (5)), and to compare the results obtained with those of $\left[{ }^{1-3}\right]$.

\section{Preliminaries}

This section is devoted to introducing briefly the tools which will be used in the sequel. The more detailed presentation of this material can be found in [ $\left.{ }^{4}\right]$. Let us introduce the differential operator $L_{f}$ associated with the function $f(x)$ :

$$
L_{f}=\sum_{i=1}^{n} f_{i} \frac{\partial}{\partial x_{i}}\left(f_{i} \text { is the } i \text { th component of } f(x)\right) .
$$

By $L_{f} \otimes L_{g}$ we will denote the tensor product of differential operators defined by

$$
L_{f} \otimes L_{g}=\sum_{i, j=1}^{n} f_{i} g_{j} \frac{\lambda^{2}}{\partial x_{i} \partial x_{j}}
$$

and $\Delta_{f}$ will denote the following operator

$$
\Delta_{f}=I+L_{f}+\frac{1}{2 !} L_{f}^{\otimes 2}+\ldots+\frac{1}{k !} L_{f}^{\otimes k}+\ldots,
$$

where $L_{f}^{\otimes k}=L_{f} \otimes \ldots \otimes L_{f}$ ( $k$ times $)$ and $I$ is the identity operator.

The differential operator $\Delta_{f}$ can be used to express the composition of functions. More precisely, if $f: R^{n} \rightarrow R^{n}$ and $h: R^{n} \rightarrow R^{p}$ are two analytic functions on $R^{n}$, then the composition (denoted by «»)) of $h$ with $I+f$, can be expressed as

$$
h \circ(I+f) x=\left.\Delta_{f} h\right|_{x},
$$

where $\left.\right|_{x}$ denotes the evaluation at $x$. More generally,

$$
h \circ\left(I+f_{k}\right) \ldots \circ\left(I+f_{1}\right) x=\left.\Delta_{f_{1}} \cdots \Delta_{f_{k}} h\right|_{x} .
$$

The tools introduced are suitable to represent the evolution of the system (1), (2) which involve compositions of functions. 


\section{Right inverse system}

The output $y_{i}$ at $t=0$ is not affected by the inputs at $t=0$. For every output $y_{i}$, let $d_{i}$ be the order of delay, $d_{i}+1$ defined as the first instant of time at which the $i$ th output is affected at least by one input at time $t=0$. Denote by $S$ the input-output map of the system and by $z$ the shift operator, $z y(t)=y(t+1)$. Then

$$
\operatorname{diag}\left\{z^{d_{1}+1}, \ldots, z^{d_{p}+1}\right\} y(t)=S[u(t)] .
$$

We say that the system $S$ is right invertible if there exists another system $S_{R}^{-1}$ such that the input-output map of the composition of $S_{R}^{-1}$ and $S$ is identity map, $S \circ S_{R}^{-1}=I_{p}$.

This yields

$$
u(t)=S_{R}^{-1}\left[\operatorname{diag}\left\{z^{d_{1}+1}, \ldots, z^{d_{p}+1}\right\} y(t)\right] .
$$

In the sequel we shall consider only systems for which the following conditions (the conditions mentioned in the section 2) hold.

The first condition guarantees that $y_{i}\left(t+d_{i}+1\right), i=1, \ldots, p$ are linear in the input $u(t)$

$$
\begin{gathered}
\left.\Delta_{f_{0}} \otimes L_{f_{i_{v}}} \otimes \ldots \otimes L_{f_{i_{i}}} \cdot \Delta_{f_{0}}^{d_{l}}\left(h_{i}\right)\right|_{x}=0, \\
\forall x \in V, \quad \forall v \geqslant 2, \quad i_{1}, \ldots, i_{v} \in\{1, \ldots, m\}, \quad i=1, \ldots, p .
\end{gathered}
$$

Here $h_{i}$ is the $i$ th component of the vector function $h(x)$. For example, the bilinear systems and linear-analytic systems with linear output function if all $d_{i}=0$ satisfy this assumption.

Let us introduce the matrix $A(x)=\left[a_{i j}(x)\right], i=1, \ldots, p, j=1, \ldots, m$ defined by

$$
a_{i j}(x)=\left.\Delta_{f_{0}} \otimes L_{f_{f}} \cdot \Delta_{f_{0}}^{d_{t}}\left(h_{i}\right)\right|_{x}
$$

The second condition requires the following

$$
\operatorname{rank} A(x)=p, \quad \forall x \in V .
$$

These two conditions together guarantee that the equations of right inverse also belong to the class of linear-analytic systems. If they do not hold, the equations of inverse system are polynomial (not linear) in the input $\left.{ }^{5}\right]$ and this yields a very complicated control law.

The system (1), (2), provided it satisfies the assumptions (6), (7), has in $V$ a right inverse, which is defined by equations $\left[{ }^{6}\right]$

$$
\begin{aligned}
x(t+1)= & x(t)+f_{0}(x(t))-F(x(t)) A^{R}(x(t)) \delta(x(t))+ \\
& +F(x(t)) A^{R}(x(t))\left[y_{1}\left(t+d_{1}+1\right) \ldots y_{p}\left(t+d_{p}+1\right)\right]^{\mathrm{T}}, \\
u(t)= & -A^{R}(x(t)) \delta(x(t))+A^{R}(x(t))\left[y_{1}\left(t+d_{1}+1\right) \ldots y_{p}\left(t+d_{p}+1\right)\right]^{\mathrm{T}},
\end{aligned}
$$

where

$$
\delta(x)=\left[\delta_{k}(x)\right], \quad k=1, \ldots, p, \quad \delta_{k}(x)=\left.\Delta_{f_{0}}^{d_{k}+1}\left(h_{k}\right)\right|_{x} .
$$

\section{Problem solution via right inverse system}

We look for the control law such that the input-output behaviour of the composite system coincides with the input-output behaviour either of the model system (4) or (5). Let the input-output maps of the original system and the model system be denoted by $S$ and $M$, respectively, and 
the input-output map of the compensator be denoted by $C$. In that case we have

$$
S \circ C=M \text {. }
$$

If we choose

$$
C=S_{R}^{-1} \circ M,
$$

we attain the desired goal. So, to obtain the wanted control law, we must feed into the equations of the right inverse system the appropriate shifts of the outputs of the model system,

$$
\left[y_{1}\left(t+d_{1}+1\right) \ldots y_{p}\left(t+d_{p}+1\right)\right]^{\mathrm{T}}=\left[y_{1}^{*}\left(t+d_{1}+1\right) \ldots y_{p}^{*}\left(t+d_{p}+1\right)\right]^{\mathrm{T}}
$$

and then express $y_{i}^{*}\left(t+d_{i}+1\right), i=1, \ldots, p$ by $z(t)$ and $v(t)$. The latter will be done by equations of model system.

If the orders of delay $\tilde{d}_{i}$ of the model system are equal to that of the original system $d_{i}, i=1, \ldots, p$ (and so it is in the case of the models (4) and (5)), then the state of the model system $z(t)$ can be expressed by the state of the original system $x(t)$. Indeed, by (4) or (5)

$$
z(t)=\left[y_{1}^{*}(t), y_{1}^{*}(t+1), \ldots, y_{1}^{*}\left(t+d_{1}\right), \ldots, y_{p}^{*}(t), \ldots, y_{p}^{*}\left(t+d_{p}\right)\right]^{\mathrm{T}} .
$$

For every $t \geqslant 1$ the choice of controls $u(k)$ up to $t-1$ gives

$$
y_{i}(t+j)=y_{i}^{*}(t+j), \quad i=1, \ldots, p, \quad j=0, \ldots, d_{i} .
$$

From equations of composite system we get

$$
y_{i}(t+j)=\Delta_{f_{0}}^{j} h_{i} \mid x(t) \text {. }
$$

Therefore, for $t \geqslant 1$

$$
z(t)=\left[h_{1}, \Delta_{f_{0}} h_{1}, \ldots, \Delta_{f_{0}}^{d_{1}} h_{1}, \ldots, h_{p}, \Delta_{f_{0}} h_{p}, \ldots, \Delta_{f_{0}^{p}}^{d_{p}} h_{p}\right]_{\left.\right|_{x(t)} ^{\mathrm{T}}}^{\mathrm{T}} .
$$

For $t=0$, of course, we must assume that the initial state of the model (4) and (5)

$$
z(0)=\left[h_{1}, \Delta_{f_{0}} h_{1}, \ldots, \Delta_{f_{0}}^{d_{1}} h_{1}, \ldots, h_{p}, \Delta_{f_{0}} h_{p}, \ldots, \Delta_{f_{0}}^{d_{p}} h_{p}\right]_{\left.\right|_{x(0)} ^{\mathrm{T}}} .
$$

\section{Linearization}

We shall look for the control law under which the input-output behaviour of the system (1), (2) satisfying the conditions (6), (7) becomes the same as that of the linear system (4). For that, according to our approach, let us feed into the equation of the right inverse system (8) the appropriate shifts of the outputs of the linear model system (4)

$$
\begin{aligned}
x(t+1)= & x(t)+f_{0}(x(t))-F(x(t)) A^{R}(x(t)) \delta(x(t))+ \\
& +F(x(t)) A^{R}(x(t))\left[y_{1}^{*}\left(t+d_{1}+1\right) \ldots y_{p}^{*}\left(t+d_{p}+1\right)\right]^{\mathrm{T}}, \\
u(t)= & -A^{R}(x(t)) \delta(x(t))+A^{R}(x(t))\left[y_{1}^{*}\left(t+d_{1}+1\right) \ldots y_{p}^{*}\left(t+d_{p}+1\right)\right]^{\mathrm{T}} .
\end{aligned}
$$

As

$$
\begin{gathered}
y_{s}^{*}\left(t+d_{s}+1\right)=z_{s}^{0}\left(t+d_{s}+1\right)=z_{s}^{1}\left(t+d_{s}\right)=\ldots \\
\ldots=\sum_{k=1}^{p} \sum_{j=0}^{d_{k}} c_{s j}^{k} z_{k}^{j}(t)+\sum_{i=1}^{p} b_{s i} v_{i}(t), \\
s=1, \ldots, p
\end{gathered}
$$

from equations of system (4) and

$$
z_{k}^{j}(t)=\left.\Delta_{f_{0}}^{j} h_{k}\right|_{x(t)}, \quad k=1, \ldots, p, \quad j=0, \ldots, d_{k}
$$


from (9), we get

$$
\begin{aligned}
x(t+1) & =x(t)+f_{0}(x(t))-F(x(t)) A^{R}(x(t)) \delta(x(t))+ \\
& +F(x(t)) A^{R}(x(t)) B v(t)+ \\
& +F(x(t)) A^{R}(x(t)) \sum_{k=1}^{p} \sum_{j=0}^{d_{k}}\left[c_{1 j}^{k} \Delta_{f_{0}}^{j} h_{k} \ldots c_{p j}^{k} \Delta_{f_{0}}^{j} h_{k}\right]_{\left.\right|_{x(t)} ^{\mathrm{T}}}^{\mathrm{T}}, \\
u(t) & =-A^{R}(x(t)) \delta(x(\mathrm{t}))+A^{R}(x(t)) B v(t)+ \\
& +A^{R}(x(t)) \sum_{k=1}^{p} \sum_{j=0}^{d_{k}}\left[c_{1 j}^{k} \Delta_{f_{0}}^{j} h_{k} \ldots c_{p j}^{k} \Delta_{f_{0}}^{j} h_{k}\right]_{\left.\right|_{x(t)} ^{\mathrm{T}}} .
\end{aligned}
$$

The output equation of the compensator (10) coincides with the feedback under which the input-output behaviour of the system (1), (2) becomes the same as that of $\left.(4){ }^{1}\right]$. Here $B=\left[b_{s i}\right]$.

\section{Decoupling}

Let us now feed into the equations of the right inverse system (8) the appropriate shifts of the outputs of the decoupled model system (5)

$$
\begin{aligned}
x(t+1) & =x(t)+f_{0}(x(t))-F(x(t)) A^{R}(x(t)) \delta(x(t))+ \\
& +F(x(t)) A^{R}(x(t))\left[y_{1}^{*}\left(t+d_{1}+1\right) \ldots y_{p}^{*}\left(t+d_{p}+1\right)\right]^{\mathrm{T}}, \\
u(t) & =-A^{R}(x(t)) \delta(x(t))+A^{R}(x(t))\left[y_{1}^{*}\left(t+d_{1}+1\right) \ldots y_{p}^{*}\left(t+d_{p}+1\right)\right]^{\mathrm{T}} .
\end{aligned}
$$

As

$$
\begin{gathered}
y_{s}^{*}\left(t+d_{s}+1\right)=z_{s}^{0}\left(t+d_{s}+1\right)=z_{s}^{1}\left(t+d_{s}\right)=\ldots \\
\ldots=\sum_{j=0}^{d_{s}} c_{j}^{s} z_{s}^{j}(t)+\left(m^{s}+\sum_{j=0}^{d_{s}} m_{j}^{s} z_{s}^{j}(t)\right) v_{s}(t), \\
s=1, \ldots, p
\end{gathered}
$$

from equations of system (5) and

$$
z_{k}^{j}(t)=\left.\Delta_{f_{0}}^{j} h_{k}\right|_{x(t)}, \quad k=1, \ldots, p, \quad j=0, \ldots, d_{k}
$$

from (9), we get

$$
\begin{aligned}
& x(t+1)=x(t)+f_{0}(x(t))-F(x(t)) A^{R}(x(t)) \delta(x(t))+ \\
& +F(x(t)) A^{R}(x(t))\left[\sum_{j=0}^{d_{1}} c_{j}^{1} \Delta_{f_{0}}^{j} h_{1} \ldots \sum_{j=0}^{d_{p}} c_{j}^{p} \Delta_{f_{0}}^{j} h_{p}\right]_{\left.\right|_{x(t)} ^{\mathrm{T}}}^{\mathrm{T}}+ \\
& +F(x(t)) A^{R}(x(t))\left[\left(m^{1}+\sum_{j=0}^{d_{1}} m_{j}^{1} \Delta_{f_{0}}^{j} h_{1}\right) v_{1}(t) \ldots\right. \\
& \left.\ldots\left(m^{p}+\sum_{j=0}^{d_{p}} m_{j}^{p} \Delta_{f_{0}}^{j} h_{p}\right) v_{p}(t)\right]_{\mid x(t)}^{\mathrm{T}}, \\
& u(t)=-A^{R}(x(t)) \delta(x(t))+A^{R}(x(t))\left[\sum_{j=0}^{d_{1}} c_{j}^{1} \Delta_{f_{0}}^{j} h_{1} \ldots \sum_{j=0}^{d_{p}} c_{j}^{p} \Delta_{f_{0}}^{j} h_{p}\right]_{\left.\right|_{x(t)}}^{\mathrm{T}}+ \\
& +A^{R}(x(t))\left[\left(m^{1}+\sum_{j=0}^{d_{4}} m_{j}^{1} \Delta_{f_{0}}^{j} h_{1}\right) v_{1}(t) \ldots\right. \\
& \left.\cdots\left(m^{p}+\sum_{j=0}^{d_{p}} m_{j}^{p} \Delta_{f_{0}}^{j} h_{p}\right) v_{p}(t)\right]_{\left.\right|_{x(t)}}^{\mathrm{T}}
\end{aligned}
$$


The output equation of the compensator (11) coincides with the feedback under which the input-output behaviour of the system (1), (2) becomes the same as that of (5) $\left[{ }^{2,3}\right]$.

\section{Conclusions}

In this paper we have tackled the problems of linearization and decoupling for the right invertible discrete-time linear-analytic system. The looked for dynamic open loop control law can be given by the equations of right inverse system, if we feed into it the appropriate shifts of outputs of linear or decoupled model systems.

It turns out that the static part of the open loop control laws coincides with corresponding feedback controls. The reason lies probably in the following. In (10) and (11) by $x(t)$ we mean the state of the right inverse. Since the states of the system and its right inverse coincide if $u(t)$ is given by $(10 \mathrm{~b})((11 \mathrm{~b}))$, the output equation of $(10)((11))$ can be interpreted as the feedback control if we mean by $x(t)$ the state of the original system under control (10b) ((11b)).

\section{REFERENCES}

1. Monaco, S., Normand-Cyrot, D. Int. J. Contr., 38, № 1, 245-261 (1983).

2. Monaco, S., Normand-Cyrot, D. Lect. Notes Contr. and Inf. Sci., 63, 364-377 (1984).

3. Kotta, O. Prepr. AFCET Congress «Automatique 85». Toulouse, 1985.

4. Normand-Cyrot, D. In: Proc. 1982 American Control Conference. San Francisco, $1982, \quad 466-471$.

5. Kotta, O. Control-Theory and Advanced Technology, 2, № 4, 619-625 (1986).

6. Kotta, O. Proc. Acad. Sci. ESSR. Phys. Math., 35, № 4, 425-431 (1986).

Academy of Sciences of the Estonian SSR, Institute of Cybernetics

Received Jan, 6, 1987

\section{Olle KOTTA}

\section{DISKREETSE LINEAAR-ANALOUTILISE SUSTEEMI LINEARISEERIMINE JA. DEKOMPONEERIMINE PAREMPOOLSE POOORDSUSTEEMI ABIL}

On vaadeldud süsteemi tagasiside abil lineariseerimise ja dekomponeerimise ülesandeid ning leitud nende seos parempoolse pöördsüsteemiga diskreetsete lineaar-analüütiliste süsteemide klassi jaoks. On näidatud, et parempoolne pööratavus on nimetatud ülesannete lahendamise piisavaks tingimuseks. Paremalt pööratavate süsteemide jaoks saadakse otsitav tagasiside parempoolse pöördsüsteemi väljundvõrrandi abil, kui sisenditeks vōtta lineaarse vổi dekomponeeritud süsteemi vạaljundid șobịivatẹ (mittelineaarse süsteemi strukțuuri poolt mạäratud) nịhetega.

\section{Юлле КОТТА}

\section{ЛИНЕАРИЗАЦИЯ И РАСЩЕПЛЕНИЕ ЛИНЕИНО-АНАЛИТИЧЕСКОИ СИСТЕМЫ С ДИСКРЕТНЫМ ВРЕМЕНЕМ С ПОМОЩЬЮ ПРАВОИ ОБРАТНОИ СИСТЕМЫ}

Решаются задачи линеаризации и расщепления вход-выходного отображения системы с помощью статистической обратной связи и раскрывается их связь с правой обратной системой для подкласса линейно-аналитических систем с дискретным временем. Показано, что обратимость справа систем является достаточным условием для решения рассматриваемых задач. Для обратимых справа систем искомое управление определяется выходным уравнением правой обратной системы, если подставить в качестве входов в это уравнение подходящие (определенные структурой нелинейной системы) сдвиги выходов заданной линейной или расщепленной систем соответственно. 